\title{
RESEARCH NOTE \\ Strategy for suppressing redox stress during tomato (Solanum lycopersicum L.) seed germination
}

\author{
Pablo Misael Arce-Amezquita, Kevin Max-Rodriguez, Ayenia Carolina \\ Rosales-Niebla, and Francisco Higinio Ruiz-Espinoza \\ Pharmacognosy laboratory, Universidad Autónoma de Baja California Sur. La Paz, B.C.S., México.
}

\begin{abstract}
P.M. Arce-Amezquita, K. Max-Rodriguez, A.C. Rosales-Niebla, and F.H. Ruiz-Espinoza. 2019. Strategy for suppressing redox stress during tomato (Solanum lycopersicum) seed germination. Cien. Inv. Agr. 46(3): 286-294. A series of pyrimidinol-based compounds have been synthesized and evaluated for their ability to increase seedling biomass during seedling development. The compounds have the ability to reduce oxidative stress catalytically as natural phenolic antioxidants such as $\alpha$-tocopherol do, but more efficiently. As a result, a compound with an appropriate structure (lipophilicity) effectively reduces the oxidative stress generated during seedling development, thus increasing biomass accumulation. Tomato seeds were pretreated with the synthesized antioxidants Py1C, Py8C and Py12C using acetone as the vehicle for application. None of the analogs tested affected total germination or hypocotyl dry biomass; however, seed treatment with Py8C and Py12C successfully increased radicle dry biomass by, on average, $44 \%$ and $88 \%$, respectively. Compounds with these properties may be useful for the production of seedlings with enhanced characteristics such as vigor and stress resistance.
\end{abstract}

Keywords: Antioxidants, dry biomass, germination, oxidative stress, pyrimidinol.

\section{Introduction}

Oxidative stress is linked to the electron transport chain in the membranes of mitochondria and chloroplasts during ATP production. Therefore, numerous energetically demanding physiological processes, such as germination and seedling development, are associated with oxidative stress (Bailly, 2004). It is well known that mitochondria

Received Sep 03, 2018. Accepted Jun 11, 2019.

Corresponding author: fruiz@uabcs.mx are the principal subcellular compartments of oxygen consumption and the principal source of reactive oxygen species (ROS) (Puntarulo et al., 1988). Most of the ATP required for the early stages of development comes from mitochondria; therefore, the generation of ROS during this process is mainly associated with cellular respiration. At later stages of development, photophosphorylation in chloroplasts becomes the main source of ATP to cover the energy requirements of proper plant development; then, chloroplasts also become a primary source of ROS (Asada, 2006). Plants are equipped with a series of proteins including 
superoxide dismutase, catalase and glutathione peroxidase that mitigate the formation of ROS during ATP production. However, during higher oxidative stress, overproduction of ROS exceeds the detoxification capacity of these proteins, causing damage to important biomolecules such as lipids, proteins and nucleic acids (Dat et al., 2000). To protect these important biomolecules from damage, plants also contain small molecules such as ascorbic acid (vitamin C) and phenolic compounds such as $\alpha$-tocopherol (vitamin E), flavonoids, tannins and phenolic acids that play an important role in oxidative damage mitigation. The production (qualitative and quantitative) and performance of these compounds in the plant are significantly influenced by the environmental (Campos-Vargas et al., 2012; Gutiérrez-Tlahque et al., 2018) and nutritional (Yañez-Mansilla et al., 2014) conditions where the plant grows and develops. These small molecules are distributed within cells according to physicochemical properties such as lipophilicity. These proteins and small molecules are considered the antioxidant defense mechanism in cells. However, when the damage to biomolecules cannot be mitigated and is too extensive, cells become apoptotic (Lenaz et al., 1998).

The correct functioning of mitochondria and chloroplasts, mainly the electron transport chain, is primarily attributable to the integrity of the biomolecules that form them. These two organelles are of great interest for plant health. One strategy for achieving the correct functioning of mitochondria and chloroplasts is the application of substances with antioxidant activities greater than those of natural phenolic antioxidants, in order to increase seedling antioxidant defenses (Arce et al., 2011). Recently, pyrimidinol-based antioxidants have been demonstrated to be more stable and effective than phenolic antioxidants due to their structural characteristics. The presence of an amino group at the para position to the hydroxyl group and of nitrogen atoms as part of the aromatic ring gives these compounds lower oxygen-hydrogen bond dissociation energy and higher ionization potentials (Pratt et al., 2001; Valgimigli et al., 2003; Wijtmans et al., 2003). This particular arrangement of atoms gives them higher ROS-inhibition ability and more stability to air than those of phenolic antioxidants (Arce et al., 2012; Khdour et al., 2013).

The application of substances with such properties might protect important biomolecules and support ATP production, thereby maintaining the maximum efficiency of cellular division in order to accumulate biomass. Therefore, the objective of this work was the preparation and evaluation of the effects of Py1C and two new pyrimidinol-based compounds with enhanced antioxidant properties on tomato seed germination. Moreover, these compounds were evaluated for their effect on dry biomass accumulation as an indirect indication of cytoprotection against oxidative stress.

\section{Materials and methods}

\section{Synthesis}

All reagents and solvents used herein were purchased from Sigma-Aldrich and were used without further purification. Column chromatography was carried out using silica gel (60 $\AA$ particle size, 230-240 mesh). Analytical thin layer chromatography (TLC) separations were carried out on glass plates coated with silica gel (60 $\AA$ particle size F254). The TLC chromatograms were developed using UV irradiation or by immersing the plates in ceric ammonium molybdate staining solution followed by heating. Melting points were recorded on a MelTemp apparatus.

To synthesize the pyrimidinol antioxidants used in this experiment, a short pathway was developed. The strategy consisted of the addition of a guanidine compound bearing different size alkyl chains to 3-acetoxy-2,4-pentanodione, which was prepared by reacting 3-chloro-2,4-pentanodione with sodium acetate. Py1C was obtained in one 
step using $N . N^{\prime}$-dimethylguanidine. However, to obtain analogs Py8C and Py12C, further reductive methylation was performed after condensation with the corresponding guanidine compound (scheme 1).

3-acetoxy-2,4-pentanodione (1). To a stirred mixture containing $7.25 \mathrm{~g}(88.4 \mathrm{mmol})$ of sodium acetate in $30 \mathrm{~mL}$ of anhydrous dimethyl sulfoxide in a round-bottomed flask, $5.00 \mathrm{~mL}(5.95 \mathrm{~g}$; 44.2 mmol) of 3-chloro-2,4-pentanodione was added. The reaction mixture was stirred at $25^{\circ} \mathrm{C}$ for $3 \mathrm{~h}$ under nitrogen atmosphere using a magnetic stirrer (VWR®). The reaction mixture was diluted with $200 \mathrm{~mL}$ of distilled water and extracted with $300 \mathrm{~mL}$ of ethyl acetate in a separatory funnel. The organic solution was then washed with 200 $\mathrm{mL}$ of brine in a separatory funnel, dried over anhydrous $\mathrm{Na}_{2} \mathrm{SO}_{4}$ and then concentrated under diminished pressure in a rotary evaporator (BUCHI $\left.{ }^{\circ}, \mathrm{R}-114\right)$. The residue was purified by chromatography on a silica gel column. Elution was performed with an ethyl acetate/hexanes 1:4 mixture. After evaporation of the fractions containing the expected compound in a rotary evaporator, the product was obtained as an orange liquid; the yield was $4.36 \mathrm{~g}$ (62\%). Silica gel TLC $\mathrm{R} f=0.32$ using a 9:1 hexane/ethyl acetate mixture as the mobile phase.

2-(dimethylamino)-4,6-dimethylpyrimidin-5-ol (Py1C) (Nara et al., 2008). To a stirred solution containing $1.00 \mathrm{~g}$ (3.67 mmol) of 1,1-dimethylguanidine hydrosulfate in $20 \mathrm{~mL}$ of $12 \mathrm{~N} \mathrm{HCl}$ in a round-bottomed flask, $2.02 \mathrm{~g}(12.8 \mathrm{mmol})$ of 3-acetoxy-2,4-pentanodione was added in three portions every $30 \mathrm{~min}$. The reaction mixture was then stirred at $25^{\circ} \mathrm{C}$ for $16 \mathrm{~h}$ using a magnetic stirrer (VWR®). The reaction mixture was neutralized with solid $\mathrm{Na}_{2} \mathrm{CO}_{3}$ and then extracted with three $50 \mathrm{~mL}$ portions of ethyl acetate in a separatory funnel. The combined organic mixture was washed with $100 \mathrm{~mL}$ of brine in a separatory funnel, dried over anhydrous $\mathrm{Na}_{2} \mathrm{SO}_{4}$ and then concentrated under diminished pressure in a rotary evaporator (BUCHI $\left.{ }^{\circledR}, \mathrm{R}-114\right)$. The residue was purified by chromatography on a silica gel column. Elution with an ethyl acetate/hexanes/ methanol 16:3:1 mixture gave the expected compound as a yellowish solid; the yield 109 was $\mathrm{mg}$ $(18 \%)$ and the $m p=143-146{ }^{\circ} \mathrm{C}$. Silica gel TLC $\mathrm{R} f=0.20$ using a 16:3:1 ethyl acetate/hexanes/ methanol mixture as the mobile phase.

\section{4,6-dimethyl-2-(octylamino)pyrimidin-5-ol}

(2). To a stirred solution containing $1.00 \mathrm{~g}$ (4.54 $\mathrm{mmol}$ ) of 1-octhylguanidine hydrosulfate in 36 $\mathrm{mL}$ of $12 \mathrm{~N} \mathrm{HCl}$ in a round-bottomed flask, 2.51 g (15.9 mmol) 3-acetoxy-2,4-pentanodione was added in three portions every $30 \mathrm{~min}$. The reaction mixture was then stirred at $25^{\circ} \mathrm{C}$ for $16 \mathrm{~h}$ using a magnetic stirrer (VWR $®)$. The reaction mixture was neutralized with solid $\mathrm{Na}_{2} \mathrm{CO}_{3}$ and then extracted with three $50 \mathrm{~mL}$ portions of ethyl acetate in a separatory funnel. The combined organic mixture was washed with $100 \mathrm{~mL}$ of brine in a separatory funnel, dried over anhydrous $\mathrm{Na}_{2} \mathrm{SO}_{4}$ and then concentrated under diminished pressure in a rotary evaporator (BUCHI $\left.{ }^{2}, \mathrm{R}-114\right)$. The residue was purified by chromatography on a silica gel column. Elution with an ethyl acetate/ hexane/methanol 16:3:1 mixture gave the expected compound as a yellowish solid; the yield was 282 $\mathrm{mg}(25 \%)$ and $\mathrm{mp}=50-52{ }^{\circ} \mathrm{C}$. Silica gel TLC

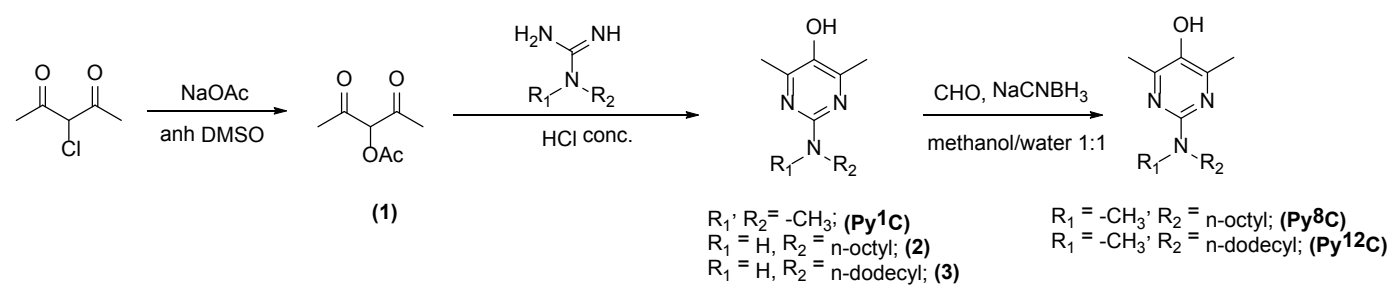

Scheme 1. Strategy followed for the synthesis of Py1C, Py8C and Py12C 
$\mathrm{R} f=0.25$ using a 16:3:1 ethyl acetate/hexane/ methanol mixture as the mobile phase.

\section{2-(dodecylamino)-4,6-dimethylpyrimidin-5-ol}

(3). To a stirred solution containing $250 \mathrm{mg}(0.87$ $\mathrm{mmol}$ ) of $\mathrm{n}$-dodecylguanidine acetate in 5.00 $\mathrm{mL}$ of $12 \mathrm{~N} \mathrm{HCl}$ in a round-bottomed flask, 550 $\mathrm{mg}$ (3.48 mmol) of 3-acetoxy-2,4-pentanodione was added in three portions every $30 \mathrm{~min}$. The reaction mixture was then stirred at $25^{\circ} \mathrm{C}$ for 16 $\mathrm{h}$ using a magnetic stirrer (VWR $®)$. The reaction mixture was neutralized with solid $\mathrm{Na}_{2} \mathrm{CO}_{3}$ and then extracted with three $50 \mathrm{~mL}$ portions of ethyl acetate in a separatory funnel. The combined organic mixture was washed with $100 \mathrm{~mL}$ of brine in a separatory funnel, dried over anhydrous $\mathrm{Na}_{2} \mathrm{SO}_{4}$ and then concentrated under diminished pressure in a rotary evaporator (BUCHI $\left.{ }^{2}, \mathrm{R}-114\right)$. The residue was purified by chromatography on a silica gel column. Elution with an ethyl acetate/ hexane 2:3 mixture gave the expected compound as a yellowish solid; the yield was $41.0 \mathrm{mg}(15$ $\%$ ) and $\mathrm{mp}=36-38^{\circ} \mathrm{C}$. Silica gel TLC $\mathrm{R} f=0.25$ using a 2:3 ethyl acetate/hexane mixture as the mobile phase.

\section{4,6-dimethyl-2-(methyl(octyl)amino)pyrimidin-} 5-ol (Py8C). To a stirred solution containing 268 $\mathrm{mg}$ (1.07 mmol) of 4,6-dimethyl-2-(octylamino) pyrimidin-5-ol in $10 \mathrm{~mL}$ of methanol/formalin 1:1 in a round-bottomed flask, $269 \mathrm{mg}$ (4.28 $\mathrm{mmol}$ ) of sodium cyanoborohydride was added. The reaction mixture was then stirred at $25{ }^{\circ} \mathrm{C}$ for $3 \mathrm{~h}$ using a magnetic stirrer (VWR $®)$. The reaction mixture was quenched with glacial acetic acid and then extracted with three $50 \mathrm{~mL}$ portions of ethyl acetate in a separatory funnel. The combined organic mixture was washed with $100 \mathrm{~mL}$ of brine in a separatory funnel, dried over anhydrous $\mathrm{Na}_{2} \mathrm{SO}_{4}$ and then concentrated under diminished pressure in a rotary evaporator (BUCHI $\left.{ }^{\circ}, \mathrm{R}-114\right)$. The residue was purified by chromatography on a silica gel column. Elution with ethyl acetate/hexanes/methanol 16:3:1 mixture gave the expected compound as a yellowish solid; the yield was $121 \mathrm{mg}(57 \%)$ and $\mathrm{mp}=34-36{ }^{\circ} \mathrm{C}$. Silica gel TLC $\mathrm{R} f=0.45$ using a 16:3:1 ethyl acetate/hexane/methanol mixture as the mobile phase.

\section{2-(dodecyl(methyl)amino)-4,6-dimethylpyrimi-} din-5-ol (Py12C). To a stirred solution containing $90 \mathrm{mg}(0.29 \mathrm{mmol})$ of 2-(dodecylamino)-4,6dimethylpyrimidin-5-ol in $4 \mathrm{~mL}$ methanol/ formalin 1:1 in a round-bottomed flask, $72 \mathrm{mg}$ $(1.16 \mathrm{mmol})$ of sodium cyanoborohydride was added. The reaction mixture was then stirred at $25^{\circ} \mathrm{C}$ for $3 \mathrm{~h}$ using a magnetic stirrer (VWR $®$ ). The reaction mixture was quenched with glacial acetic acid and then extracted with three $50 \mathrm{~mL}$ portions of ethyl acetate in a separatory funnel. The combined organic mixture was washed with $100 \mathrm{~mL}$ of brine in a separatory funnel, dried over anhydrous $\mathrm{Na}_{2} \mathrm{SO}_{4}$ and then concentrated under diminished pressure in a rotary evaporator (BUCHI $\left.{ }^{\circledR}, \mathrm{R}-114\right)$. The residue was purified by chromatography on a silica gel column. Elution with an ethyl acetate/hexane 1:9 mixture gave the expected compound as a yellowish solid; the yield was $47 \mathrm{mg}(50 \%)$ and $\mathrm{mp}=45-47^{\circ} \mathrm{C}$. Silica gel TLC $\mathrm{R} f=0.25$ using a 1:9 ethyl acetate/hexane mixture as the mobile phase

\section{Germination test}

Py1C, Py8C and Py12C were then evaluated in tomato seed germination. For the germination test, the seeds were pretreated by soaking them in acetone containing pyrimidinols Py1C, Py8C and Py12C at 200 and $1000 \mu \mathrm{M}$ concentrations for $24 \mathrm{~h}$. Per each gram of seeds, $30 \mathrm{~mL}$ of the respective solutions were used. The controls were untreated seeds and seeds pretreated with pure acetone. Seeds were filtered and dried in an oven at $40{ }^{\circ} \mathrm{C}$ for 30 min under diminished pressure before the test. The experiment was set in a completely random design that consisted of four replicates of 25 seeds per treatment and controls. To avoid disturbances in germination due to rehumidification in case of desiccation during the experiment, the seeds were placed 
on four filter paper discs (Whatman ${ }^{\mathrm{TM}}$ No. 1) at once in $9 \mathrm{~cm}$-diameter plastic Petri dishes containing $10 \mathrm{~mL}$ of distilled water. The dishes with the seeds were kept at $25{ }^{\circ} \mathrm{C}$ for 7 days in a dark germination chamber. Seeds with testa rupture were considered germinated. The obtained seedlings were separated by hypocotyl and radicle and then dried separately in an oven at $100{ }^{\circ} \mathrm{C}$ for $48 \mathrm{~h}$. The dried material was weighed in an analytical balance (Mettler Toledo $\AA$, AG245) to obtain hypocotyl and radicle dry biomass. Oneway univariate analysis of variance (ANOVA) was used to analyze the data obtained, and seed treatment was used as a fixed factor. The difference between the means was determined by the Tukey-HSD multiple range test at $P=0.05$. Mean values were considered significantly different when $P \leq 0.05$. Statistical analysis was carried out using Statistica ${ }^{\circledR}$ v. 10.0.

\section{Results}

The compounds Py1C, Py8C and Py12C were obtained with $11 \%, 8.8 \%$ and $4.7 \%$ overall yield, respectively.

None of the treatments significantly affected total germination, which was approximately $70 \%$ in the treatments and in the controls that consisted of untreated seeds and seeds soaked with pure acetone (Figure 1).

The seedlings obtained did not show a significant difference in average hypocotyl dry biomass per seedling obtained from seeds treated with analogs Py1C, Py8C and Py12C compared to the controls after 7 days of germination (Figure 2). The average hypocotyl dry biomass per seedling was approximately $1.1 \mathrm{mg} /$ hypocotyl.

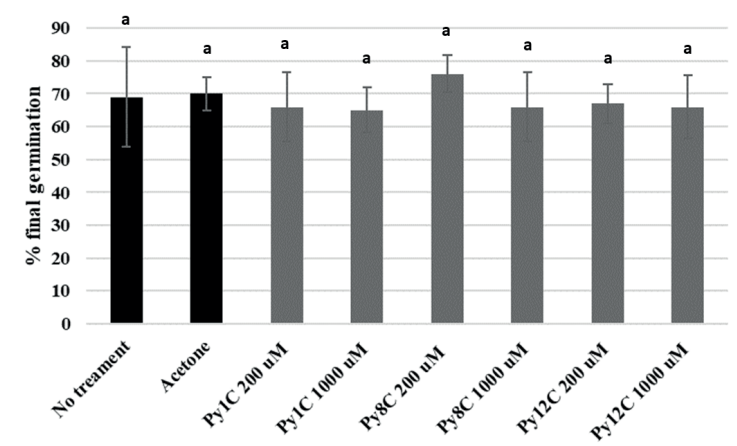

Figure 1. Effect of seed pretreatment with pyrimidinol antioxidants on final germination at 7 days. Values are means \pm SDs; different letters indicate significant differences at $\mathrm{P}<0.05$.

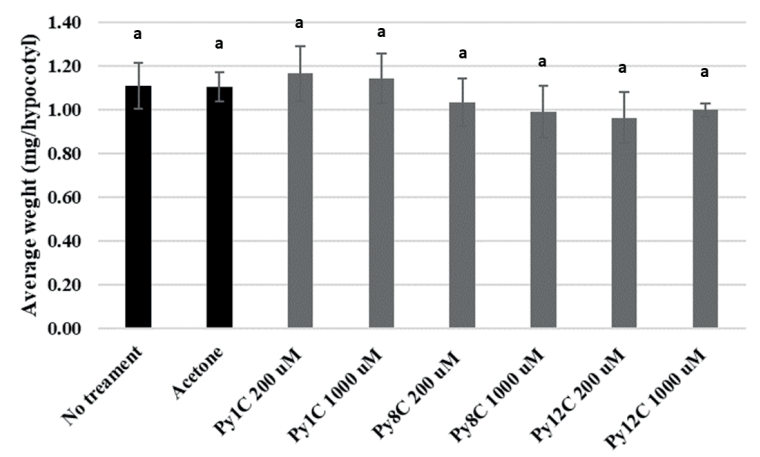

Figure 2. Effect of seed pretreatment with different concentrations of pyrimidinol antioxidants on hypocotyl dry biomass. Values are means \pm SDs; different letters indicate significant differences at $\mathrm{P}<0.05$. 
However, the average radicle dry biomass per seedling was significantly affected; analog Py8C increased it, on average, by $44 \%$ and analog Py12C, by 88 $\%$ compared to those of the controls (Figure 3). Seedlings from the controls presented an average radicle dry biomass per seedling of approximately $0.09 \mathrm{mg} / \mathrm{radicle}$, seedlings treated with Py8C presented an average radicle dry biomass per seedling of approximately $0.13 \mathrm{mg}$ / radicle and seedlings treated with Py12C presented an average radicle dry biomass per seedling of approximately 0.17 $\mathrm{mg} /$ radicle.

Seeds treated with the antioxidant Py12C showed exceptionally increased hypocotyl and radicle size compared to those of the controls among the seedlings obtained after seven days of germination in the dark at $25^{\circ} \mathrm{C}$, as shown in Figure 4.

\section{Discussion}

In an effort to obtain potent antioxidants that could be used for quenching oxidative stress, a series of three pyrimidinol analogs were synthesized. These compounds contain different-sized alkyl side chains that provide different pharmacokinetic properties in terms of lipophilicity.

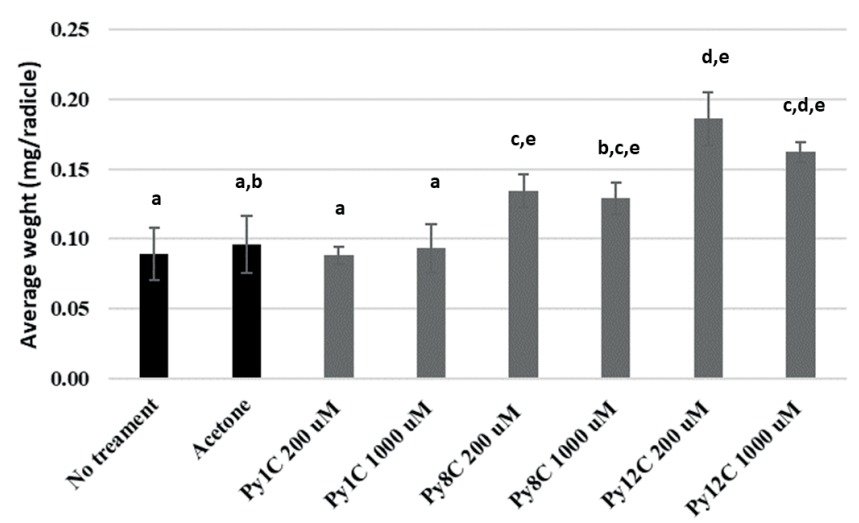

Figure 3. Effect of seed pretreatment with pyrimidinol antioxidants on radicle dry biomass. Values are means \pm SDs; different letters indicate significant differences at $\mathrm{P}<0.05$.

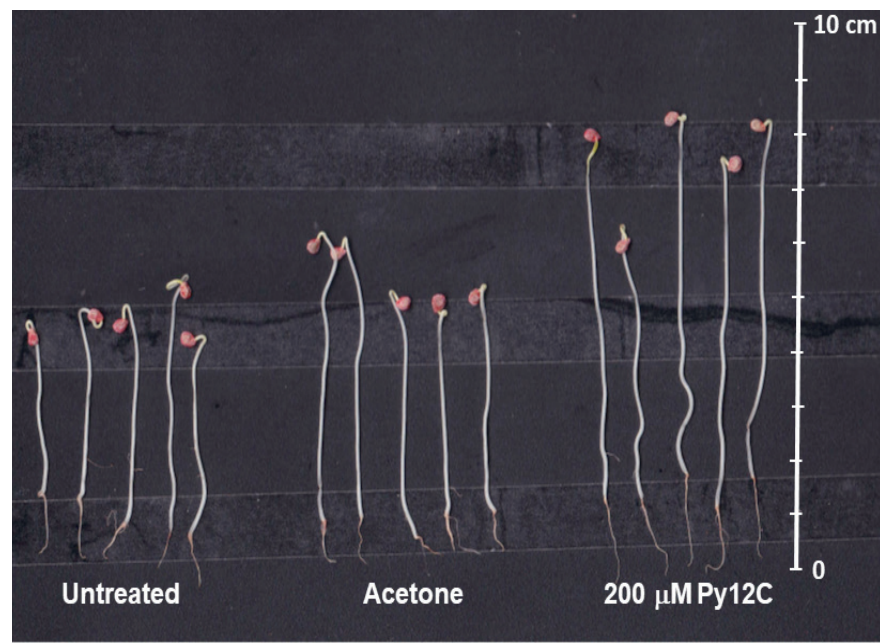

Figure 4. Effect of seed pretreatment with Py12C at $200 \mu \mathrm{M}$ on seedling size compared to controls. 
The antioxidant effect of these new pyrimidinol analogs was tested for the augmentation of biomass during the germination of tomato seeds. Interestingly, all three analogs have the same redox core, where the antioxidant chemistry happens; however, only compounds Py8C and Py12C showed an important effect on radicle dry biomass (Figure 3). Hypocotyl dry biomass was not affected after treatment with the antioxidants synthesized herein probably because there is an overproduction of ROS in radicles compared to that in hypocotyls; therefore, the antioxidant activity in radicles is more evident. This enhanced antioxidant activity is attributed to the fact that the compounds have the proper characteristics (possibly lipophilicity) that allow them to reach the mitochondria, which are the main source of oxidative stress during germination. Additionally, Py1C did not show any effect at all, probably due to the lack of uptake of this compound by the cells. These results suggest that Py8C and Py12C the cells by diffusion through the membranes.

Additionally, this series of antioxidant structures is based on a pyrimidinol moiety, which means that they are stable to air oxidation and have higher rates of oxidative stress quenching than phenol antioxidants, so only a few molecules need to reach the site of ROS generation in order to reduce oxidative stress. In addition, it is believed that antioxidants of this nature act catalytically, possibly being regenerated by vitamin $\mathrm{C}$ and the cofactor nicotine adenine dinucleotide (NADH) each time they are oxidized after quenching ROS (Liebler, 1993).

Previously, it has been shown that pretreatment of tomato seeds with natural antioxidants (b-carotene, ascorbic acid and lycopene) and the synthetic antioxidant Ambiol ${ }^{\mathrm{TM}}$ have positive effects on the shoot and root dry biomass of seedlings under drought stress. These positive effects were also observed in terms of leaf area and photosynthetic activity (Macdonald et al., 2008; Macdonald et al., 2009). Ascorbic acid has also been shown to increase dry biomass and drought resistance in wheat upon seed preconditioning (Farooq et al., 2013). Interestingly, the positive effects obtained after seed pretreatment with Ambiol ${ }^{\mathrm{TM}}$ are passed on to the next generations, even improving the production yield (Macdonald et al., 2010). Until now, aqueous solutions of antioxidants have been used for seed pretreatment, which meant that the germination process started during the treatment. In this experiment, we explored the possibility of using an organic solvent as a vehicle for the application of antioxidants. This strategy has been used previously for the application of organic compounds to dry seeds without affecting germination (Tao and Khan, 1974; O’Neill et al., 1979). Among the organic solvents, acetone has shown more compatibility with plant physiological conditions (Murphy, 1985). An important feature of using organic solvents is that the germination mechanism is not activated, allowing the possibility of sowing the seeds even months after the treatment (Khan et al., 1973). Another important aspect of using organic solvents is that compounds that typically cannot be utilized because of their poor water solubility can be applied to the seeds.

An interesting observation was the augmented size of seedlings grown from seeds treated with Py12C (Figure 4). The observed larger size correlates with the augmentation of radicle biomass; on the other hand, the hypocotyl seemed to only be elongated. Even though the hypocotyls were longer under the Py12C treatment, they had the same biomass as those in the controls. This phenomenon suggests changes in the absorption and use of water. The application of exogenous molecules that increase vigor and resistance by alleviating oxidative stress could be an important strategy for obtaining more substantial benefits from a given crop.

The main conclusions are as follows. Two new pyrimidinol antioxidants (Py8C and Py12C) were synthesized along with Py1C. Py8C and Py12C showed the ability to increase seedling radicle biomass upon application to dry seeds using acetone as the vehicle for application. 
However, Py12C was shown to be more effective than Py8C and Py1C, and the latter did not show any activity in experiments carried out in this work. These findings suggest the importance of the antioxidant chemical structure in obtaining the most appropriate compounds for application in agronomy. The tendency toward more biological activity as the lipophilicity of the side chain increases requires the preparation and evaluation of more analogs with longer alkyl side chains. The utilization of techniques for the reduction in oxidative stress during important biochemical processes for plant establishment, such as the technique presented in this investigation, ensures the maximum efficiency of energy production and utilization. Thus, antioxidants such as pyrimidinol compounds could enhance plant resistance and vigor by facilitating the proper deployment of energy (ATP) for processes such as cellular division and plant defense against biotic and abiotic stress rather than using that energy to handle damage produced by ROS.

\section{Resumen}

P.M. Arce-Amezquita, K. Max-Rodriguez, A.C. Rosales-Niebla, y F.H. Ruiz-Espinoza. 2019. Estrategia para suprimir el estrés oxidativo durante la germinación de tomate (Solanum lycopersicum). Cien. Inv. Agr. 46(3): 286-294. Una serie de compuestos basados en pirimidinoles ha sido sintetizada y evaluada en el incremento de biomasa durante desarrollo de plántulas. Estos compuestos tienen la habilidad de reducir el estrés oxidativo catalíticamente como lo hacen los compuestos antioxidantes fenólicos naturales, como el $\alpha$-tocoferol. Como resultado, un compuesto con la estructura apropiada (lipofilicidad) puede reducir eficientemente el estrés oxidativo generado durante el desarrollo de plántulas y, por consiguiente, incrementar la acumulación de biomasa. Semillas de tomate fueron pre-tratadas con antioxidantes sintetizados Py1C, Py8C y Py12C usando acetona como vehículo de aplicación. Ninguno de los análogos aplicados afectó la germinación total ni la biomasa seca de hipocótilo; sin embargo, el tratamiento de semillas con Py8C y Py12C incrementó satisfactoriamente en promedio 44 \% y $88 \%$ la biomasa seca de raíz, respectivamente. Compuestos con estas propiedades pueden ser útiles en la producción de plántulas con características mejoradas como vigor y resistencia al estrés.

Palabras clave: Antioxidantes, biomasa seca, estrés oxidativo, germinación, pirimidinol.

\section{References}

Arce P.M., O.M. Khdour, R. Goldschmidt, J.S. Armstrong, and S.M. Hecht. 2011. A strategy for suppressing redox stress within mitochondria. ACS Med. Chem. Lett. 2:608-613. doi: 10.1021/ $\mathrm{ml} 200095 \mathrm{w}$

Arce, P.M., R. Goldschmidt; O.M. Khdour, M.M. Madathil, J. Jaruvangsanti, S. Dey, D.M. Fash, J.S. Armstrong, and S.M. Hecht. 2012. Analysis of the structural and mechanistic factors in antioxidants that preserve mitochondrial function and confer cytoprotection. Bioorg. Med. Chem. 20:5188-5201. doi: 10.1016/j.bmc.2012.07.005
Asada, K. 2006. Production and scavenging of active oxygen in chloroplast and their functions. Plant Physiology 141:391-396. doi: 10.1104/ pp. 106.082040

Bailly, C. 2004. Active oxygen species and antioxidants in seed biology. Seed Sci Res 14:93-107. doi: 10.1079/SSR2004159

Campos-Vargas, R., P. Zamora, R. Contreras, H. Köhler, G. E. Zúñiga, A. Pérez-Donoso, and B.G. Defilippi. 2012. Cold storage effects on oxidative stress of cv. Red Globe table grape rachises. Cien. Inv. Agr. 39:91-104. doi: 10.7764/rcia.v39i1.81

Dat, J., S. Vandenabeele, E. Vranová, M. Van Montagu, D. Inzé, and F. Van Breusegem. 2000. Dual 
action of the active oxygen species during plant stress responses. Cell. Mol. Life Sci. 57:779795. doi: 10.1007/s000180050041

Farooq, M., M.S. Irfan, T. Aziz, I.N. Ahmad, and S.A. Cheema. 2013. Seed priming with ascorbic acid improves drought resistance of wheat. J. Agronomy \& Crop Science 199:12-22. doi: 10.1111/j.1439-037X.2012.00521.x

Gutiérrez-Tlahque, J., C.L. Aguirre-Mancilla, J.C. Raya-Pérez, J.G. Ramírez-Pimentel, R. JiménezAlvarado, and A.D. Hernández-Fuentes. 2018. Effect of climate conditions on total phenolic content and antioxidant activity of Jatropha dioica Cerv. var. dioica. Cien. Inv. Agr. 45:70-81. doi: 10.7764/rcia.v45i1.1832

Khan, A.A., K.L. Tao, and C.H. Roe. 1973. Application of chemicals in organic solvents to dry seeds. Plant Physiology 52:79-81. doi: 10.1104/pp.52.1.79

Khdour O.M., P.M. Arce, B. Roy, and S.M. Hecht. 2013. An optimized pyrimidinol multifunctional radical quencher. ACS Med. Chem. Lett., 4:724729. doi: $10.1021 / \mathrm{ml} 400130 \mathrm{z}$

Lenaz, G. 1998. Role of mitochondria in oxidative stress and ageing. Biochim. Biophys. Acta, 1366:53-67. doi: 10.1016/S00052728(98)00120-0

Liebler, D.C. 1993. The role of metabolism in the antioxidant function of vitamin E. Crit. Rev. Toxicol. 23:147-169. doi: 10.3109/10408449309117115

Macdonald, M.T., L.R. Rajasekaran, J. Hoyle, and A.R. Robinson. 2008. Seed pre-conditioning with ambiol $\AA$, a derivative of 5-hydroxybenzimidazole, acclimates tomato (Lycopersicon esculentum mill.) seedlings to drought. Acta Hort. 774:355-362. doi: 10.17660/ ActaHortic.2008.774.49

MacDonald, M.T., R.R. Lada, A.R. Robinson, and J. Hoyle. 2009. Seed Preconditioning with natural and synthetic antioxidants induces drought tolerance in tomato seedlings. Hortscience 44:13231329. doi: 10.21273/HORTSCI.44.5.1323

MacDonald, M.T., R. Rajasekaran, A. Lada, R. Robinson, and J. Hoyle. 2010. The benefits of ambiol in promoting germination, growth, and drought tolerance can be passed on to next-generation tomato seedlings. J Plant Growth Regul. 29:357365. doi: $10.1007 / \mathrm{s} 00344-010-9148-\mathrm{x}$

Murphy, J.B. 1985. Acetone production during the germination of fatty seeds. Physiologia Plantarum 63:231234. doi: 10.1111/j.1399-3054.1985.tb01908.x

Nara, S.J., M. Jha, J. Brinkhorst, T.J. Zemanek, and D.A. Pratt. 2008. A simple Cu-catalyzed coupling approach to substituted 3-pyridinol and 5-pyrimidinol antioxidants. J. Org. Chem. 73:9326-9333. doi: 10.1021/jo801501e

O’Neill, N.R., G.C. Papavizas, and J.A. Lewis. 1979. Infusion and translocation of systemic fungicides applied to seeds in acetone. Phytopatology 69:690-694. doi: 10.1094/Phyto-69-690

Pratt, D.A., G.A. DiLabio, G. Brigati, G.F. Pedulli, and L. Valgimigli. 2001. 5-Pyrimidinols: Novel chain-breaking Antioxidants More Effective than Phenols. J. Am. Chem. Soc. 123:4625-4626. doi: 10.1021/ja0056791

Puntarulo, S., R.A. Sanchez, and A. Boveris. 1988. Hydrogen peroxide metabolism in soybean embryonic axes at the onset of germination. Plant Physiology 86:626-630. doi: 10.1104/pp.86.2.626

Tao, K.L., and A.A. Khan. 1974. Penetration of dry seeds with chemicals applied in acetone. Plant Physiology 54:956-958. doi: 10.1104/ pp.54.6.956

Valgimigli, L., G. Brigati, G.F. Pedulli, G.A. DiLabio, M. Mastragostino, C. Arbizzani, and D.A. Pratt. 2003. The effect of ring nitrogen atoms on the homolytic reactivity of phenolic compounds: understanding the radical-scavenging ability of 5-pyrimidinols. Chem. Eur. J. 9:4997-5010. doi: 10.1002/chem. 200304960

Wijtmans, M., D.A. Pratt, L. Valgimigli, G.A. DiLabio, G.F. Pedulli, and N.A. Porter. 2003. 6-Amino3-pyridinols: towards diffusion-controlled chainbreaking antioxidants. Angew. Chem. Int. Ed., 42:4370-4373. doi: 10.1002/anie.200351881

Yañez-Mansilla, E., P. Cartes, M. Reyes-Díaz, A. Ribera-Fonseca, and M. Alberdi. 2014. Photosynthetic and antioxidant performance are differentially affected by short-term nitrogen supply in highbush blueberry cultivars. Cien. Inv. Agr. 41(1):61-70. doi: 10.4067/S071816202014000100006 